\title{
Effect of hydrostatic pressure on viscous remanent magnetization in magnetite-bearing specimens
}

\author{
Paul R. Kelso ${ }^{i}$ and Subir K. Banerjee \\ Department of Geology and Geophysics, Institute for Rock Magnetism, University of Minnesota, Minneapolis, MN
}

\begin{abstract}
Rocks at depth in the crust acquire a viscous (i.e., time-dependent) magnetization under the pressure-temperature conditions at which they reside. There have been numerous studies on the effect of temperature on viscous magnetization but little work has been performed on the effect of hydrostatic pressure. We have studied viscous remanent magnetization at $22^{\circ} \mathrm{C}$ in a $0.1 \mathrm{mT}$ field at 0.1 and $100 \mathrm{MPa}$ for natural and synthetic multidomain magnetite. The viscous remanent magnetization was found to increase nearly linearly with $\log$ (time) at both pressures. There was little change in the rate of viscous acquisition between 0.1 and $100 \mathrm{MPa}$ over the multidomain grain size range studied. Thus for rocks buried at depth in the earth the enhancement of magnetic viscosity by thermal fluctuations will dominate over effects due to hydrostatic pressure.
\end{abstract}

\section{Introduction}

The source of long wavelength magnetic anomalies is a subject of much debate among geophysicists (e.g., see reviews by Maybew and LeBrecque, 1987 and Hahn and Roeser, 1989). Based on thermal and petrologic evidence and magnetic anomaly modeling, most workers agree that the source must lie at some depth $(0-100 \mathrm{~km})$ in the earth's lithosphere. The magnetization of rocks exposed at the surface are usually not large enough to explain the observed anomalies (Schlinger, 1985; Williams et al., 1985; Toft and Haggerty, 1988; Shive and Fountain, 1988; Wasilewski and Warner, 1988; Kelso et al., 1993). Thus a variety of mechanisms have been proposed for the anomaly sources: 1) the mantle is magnetic; 2) highly magnetic rock types exist that have not been sampled adequately; 3) magnetic susceptibility is enhanced at elevated temperature (Hopkinson effect); 4) magnetic viscosity is enhanced at elevated temperature; 5) mafic granulites are the source. One variable that has not been considered in most previous analyses is the effect of pressure on the rocks magnetic properties (for a review see Kelso, 1993).

Since the magnetic sources reside at depth they are at elevated pressure due to overlying rock units and tectonic forces. Pressure due to hydrostatic loading at $30-40 \mathrm{~km}$ may be $1000 \mathrm{MPa}$ or more, whereas differential stresses in the lower crust are generally less than $200 \mathrm{MPa}$ (Fountain, 1989). Hydrostatic pressures, up to $6000 \mathrm{MPa}$, cause the Curie temperature $\left(\mathrm{T}_{\mathrm{c}}\right)$ of magnetite to increase at the near-linear rate of approximately $2^{\circ} \mathrm{C}$ per $100 \mathrm{MPa}$ (Samara and Giardini, 1969; Schult, 1970). The saturation magnetization $\left(J_{S}\right)$ also

\footnotetext{
${ }^{\mathbf{1}}$ Now at Department of Geology and Physics, Lake Superior State University, Sault Ste. Marie, MI
}

Copyright 1995 by the American Geophysical Union.

Paper number 95GL01791

0094-8534/95/95GL-01791\$03.00 increases with hydrostatic pressure but at a rate of $<0.1 \%$ per $100 \mathrm{MPa}$ at room temperature. This has been attributed to the displacement of $T_{C}$ to higher temperature and thus to a shifting of the $J_{S}$ vs. $T$ curve (Samara and Giardini, 1969). Therefore elevated temperature values of $J_{S}$ and $T_{c}$ measured at atmospheric pressure should be similar to those for samples at corresponding temperatures, but at elevated pressure, within the earth.

There have been a variety of studies examining the changes in magnetic susceptibility and remanent magnetization as a function of uniaxial stress and occasionally for hydrostatic pressure. Experiments on the effect of hydrostatic pressure on magnetic susceptibility have given conflicting results (Nulman et al., 1978; Martin, 1980; Kapicka, 1990 \& 1992). It seems likely from these results that magnetic susceptibility at elevated pressure $(0-250 \mathrm{MPa})$ will be within $10 \%$ of the susceptibility measured at room pressure. Thus, pressure should not greatly affect the induced magnetization. Hydrostatic pressure could affect domain wall pinning by increasing magnetoelastic energies relative to magnetocrystalline energies as observed by Nagata and Kinoshita (1967). We are not aware of any study that has examined the acquisition of a thermal remanent magnetization, or even an isothermal remanent magnetization, while under hydrostatic pressure.

The effect of pressure on the experimental acquisition of viscous magnetization has been the subject of only a few cursory studies (Pozzi, 1970; Bezuglaya et al., 1973; Spörer, 1984). All studies observed an increase in the rate of acquisition of viscous magnetization, from two to six times, with the application of uniaxial pressures of less than $50 \mathrm{MPa}$. There was an increase in the viscous acquisition rate for uniaxial compression regardless of its orientation relative to the applied field. The largest increase was for uniaxial compression perpendicular to the applied field.

Previous studies concerning the source of long wavelength magnetic anomalies have not generally considered the effect of stress although it is known that all rocks at depth in the earth are in some elevated state of stress. The direct application of the above viscous magnetization studies to understanding the source of long wavelength magnetic anomalies is difficult since the source material responsible for the magnetic anomalies is likely to be relatively pure magnetite whereas previous studies were on titanomagnetites. Also the stress field of the lower crust is likely dominated by hydrostatic pressure while the above studies concentrated on the effect of uniaxial compression on viscous acquisition. This is the first study on the effect of true hydrostatic pressure on viscous magnetization. Additionally, magnetites with different multidomain grain sizes were studied to examine the stress dependence of viscous acquisition as a function of magnetic grain size. 
Table 1. Magnetic properties and viscosity coefficients of the Austrailian granulite sample (246B3b) and the three glass ceramic samples. Js - saturation magnetization; Jrs - saturation remanent magnetization; Hc - coercivity; Hcr - coercivity of remanence; Tc - Curie temperature; $\mathrm{Sa}(0.1)$ - the viscosity coefficient at $0.1 \mathrm{MPa}$ as determined from the best fit line to the data in Figures 1 through $4 ; \mathrm{Sa}(100)$ - the viscosity coefficient at $100 \mathrm{MPa}$ as determined from the best fit line to the data in Figures 1 through 4.

\begin{tabular}{|c|c|c|c|c|c|c|c|c|c|c|c|c|}
\hline Sample Number & $\begin{array}{c}\text { Mass } \\
{[\mathrm{kg}]}\end{array}$ & $\begin{array}{c}\text { Susceptlbility } \\
\text { [m3/kg] }\end{array}$ & {$\left[A^{*} m^{*} m / k g\right]$} & {$\left[\begin{array}{c}J \mathbf{s s} \\
{\left[\mathbf{A}^{*} \mathbf{m}^{*} \mathbf{m} / \mathbf{k g}\right]}\end{array}\right.$} & $\begin{array}{c}\text { Hc } \\
\text { [mT] }\end{array}$ & $\begin{array}{c}\text { Her } \\
{[\mathbf{m T}]}\end{array}$ & $\frac{J r s}{J s}$ & $\frac{\text { Her }}{\text { Hc }}$ & $\begin{array}{c}\mathbf{T c} \\
{\left[{ }^{\circ} \mathrm{C}\right]}\end{array}$ & $\begin{array}{c}\mathrm{Sa}(0.1) / \mathrm{Js} \\
{[1 / \mathrm{hr}]}\end{array}$ & $\begin{array}{c}\mathrm{Sa}(100) / \mathrm{Js} \\
{[1 / \mathrm{hr}]}\end{array}$ & $\frac{\mathrm{Sa}(100)-\mathrm{Sa}(0.1)}{\mathrm{Sa}(0.1)}$ \\
\hline $246 \mathrm{BBb}$ & $1.73 \mathrm{E}-03$ & 2.39E-05 & 2.87 & 0.0997 & 2.82 & 14.3 & 0.035 & 5.07 & 561 & $1.91 \mathrm{E}-05$ & $3.05 \mathrm{E}-05$ & $+60.0 \%$ \\
\hline H104 & $1.78 \mathrm{E}-04$ & $3.42 \mathrm{E}-04$ & 18.7 & 3.67 & 21.9 & 50.3 & 0.197 & 2.3 & 565 & $8.83 \mathrm{E}-05$ & 9.91E-05 & $+12.3 \%$ \\
\hline GC2a & 4.35E-04 & $7.10 \mathrm{E}-05$ & 10.4 & 0.948 & 9.6 & 30 & 0.091 & 3.12 & 572 & $3.51 \mathrm{E}-05$ & $2.46 \mathrm{E}-05$ & $-30.0 \%$ \\
\hline GC3a & $6.36 \mathrm{E}-04$ & 4.32E-05 & 5.45 & 0.357 & 7.08 & 28.8 & 0.066 & 4.06 & 566 & 4.27E-05 & $2.63 \mathrm{E}-05$ & $-38.5 \%$ \\
\hline
\end{tabular}

\section{Sample Description and Experimental Procedure}

The specimens used in this study included a granulite grade lower crustal sample from the Arunta Block of Central Australia (Kelso et al., 1993) and synthetic glass ceramic samples prepared by the technique of Worm and Markert (1987a). The samples' magnetic properties correspond to those of relatively pure magnetite $(<5 \%$ cation substitution for iron) with a magnetic grain size range from pseudo-single domain to multidomain as inferred from the magnetic properties (table 1). Hysteresis loops and magnetic susceptibility measurements performed before and after elevated pressure experiments confirm that no phase or microstructural changes occur during the course of the experiments.

Viscous remanent magnetization (VRM) acquisition experiments were performed at $0.1 \mathrm{MPa}$ (atmospheric pressure) and $100 \mathrm{MPa}(1 \mathrm{~kb})$. All experiments were performed at $22^{\circ} \mathrm{C}$. Remanence measurements were always made in zero field at 0.1 $\mathrm{MPa}$ with a $2 \mathrm{G}$ cryogenic magnetometer. The samples were initially thermally demagnetized at $600-620^{\circ} \mathrm{C}$ in flowing helium. Thermal demagnetization was chosen as the initial state as it more closely simulates the magnetic state in nature than does the AF demagnetized initial state used in the previously mentioned studies. Thermally demagnetized samples were oriented in the VRM acquisition apparatus and stored in zero field $(<0.05 \mu \mathrm{T})$ for approximately $15 \mathrm{hr}$. before VRM experiments began. VRM was acquired in a field of $100 \pm 0.5 \mu \mathrm{T}(1 \mathrm{Oe})$ for a specified time $(2-50 \mathrm{hr}$.). There was approximately a $30 \mathrm{~min}$. lag time between turning off the acquisition field and measurement of the VRM due to the time required for the samples to reach atmospheric pressure, be

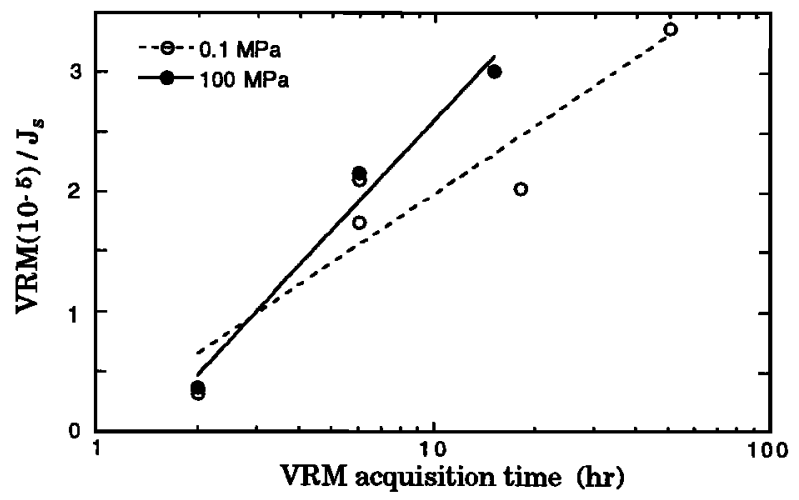

Figure 1. Viscous remanence acquisition data for natural granulite sample 246B3b at ambient conditions (O.1 MPa and $\left.22^{\circ} \mathrm{C}\right)$ and at elevated pressure $\left(100 \mathrm{MPa}\right.$ and $\left.22^{\circ} \mathrm{C}\right)$. removed from the pressure vessel, and positioned in the magnetometer. The samples were in zero field for the majority of this time, but were exposed to the earth's field, $50 \mu \mathrm{T}$, for about two minutes while the pressure vessel was disassembled during the early portion of the lag time. During pressurization and pressure release the samples were in zero field $(<0.05 \mu \mathrm{T})$. The lag time between VRM acquisition and its measurements was not necessary for the $0.1 \mathrm{MPa}$ experiments but a similar lag time was maintained for comparison purposes. Monitoring of the VRM decay found that generally $<10 \%$ of the remanence was lost between 5 and 90 minutes after removal of the field. The acquired VRM measurement was corrected for any remanence remaining after the initial thermal demagnetization by subtracting the initial remanence from the remanence after VRM acquisition.

The cylindrical pressure vessel was made of non-magnetic titanium that was wound with an insulated wire to form a solenoid over it. A constant DC current was applied to produce an axial field of $100 \pm 0.5 \mu \mathrm{T}$. The pressure vessel was mounted horizontally on an aluminum frame that was surrounded by a two-layer mu-metal shield. With the current off, the stray fields in the pressure vessel were $<0.05 \mu \mathrm{T}$. True hydrostatic pressure was transmitted to the samples using an argon gas system. Pressure was achieved by using a Haskel pumping system and occasionally maintained using an oil pump intensifier. Pressure variations during a given experiment were generally less than $\pm 5 \mathrm{MPa}$. It took 5 to 10 minutes for the samples to reach $100 \mathrm{MPa}$ from atmospheric pressure, or vice versa.

\section{Results and Discussion}

The VRM acquisition data at $0.1 \mathrm{MPa}$ and $100 \mathrm{MPa}$ of one natural and three synthetic samples are plotted in figures 1 through 4. Note that the data is plotted on a semilog scale with the magnetization normalized by the saturation magnetization for the individual samples. There is an approximately linear increase in the acquired VRM with $\log ($ time) for all samples, in agreement with general theories of thermal fluctuation mechanisms for viscous magnetization (reviewed by Dunlop, 1973). The viscosity coefficients $\left(S_{\mathfrak{a}}\right)$ of individual samples, defined as the slope of the best fit line to this data (e.g., Dunlop, 1973; Moskowitz, 1985), is reported in table 1 for both the 0.1 and $100 \mathrm{MPa}$ experiments. The viscosity coefficients are very similar at the two pressures for all of the samples, with a slight increase for some samples and a decrease for others (table 1). This is true for both the natural and synthetic samples. 


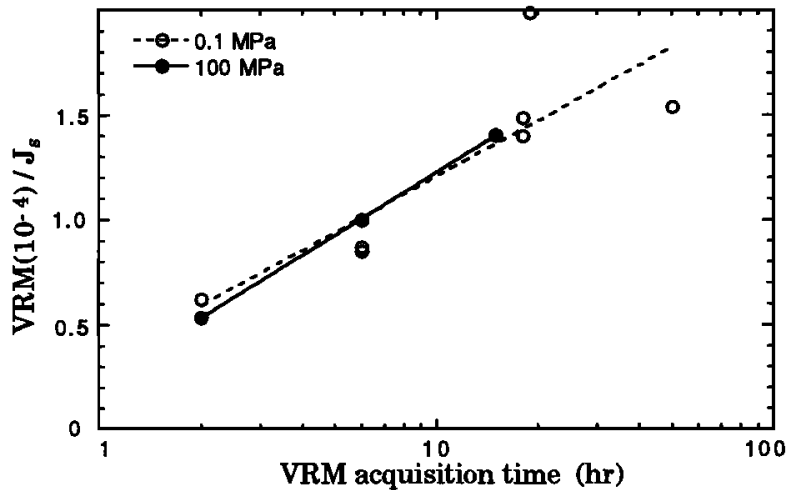

Figure 2. Viscous remanence acquisition data for glass ceramic sample $\mathrm{H} 104$ at ambient conditions (O.1 MPa and $\left.22^{\circ} \mathrm{C}\right)$ and at elevated pressure $\left(100 \mathrm{MPa}\right.$ and $\left.22^{\circ} \mathrm{C}\right)$.

These results are in great contrast to the results on the effect of uniaxial compression on VRM mentioned above. Uniaxial compression experiments found an increase in VRM of several times between room temperature and $50 \mathrm{MPa}$ for titanomagnetites (Pozzi, 1970; Bezuglaya et al., 1973; Spörer, 1984). The relatively minor change of viscosity with hydrostatic pressure compared to uniaxial pressure is consistent with the smaller changes observed in the magnetic material properties of magnetite under hydrostatic conditions (e.g., various remanent magnetic states and magnetic susceptibility). The gradients associated with differential pressures (e.g., uniaxial compression) will likely contribute to diffusion of ions, vacancies, and defects, which can affect the material's magnetic properties. Uniaxial stress also produces deformation and an increase in the defect density. Such diffusion will cause magnetic domain movements to minimize the changes in the magnetic energies associated with the diffusing species. This diffusion will likely contribute to magnetic viscosity as the domains move in the presence of a biasing field. Pozzi (1970) argues that diffusion mechanisms are the source of the enhanced viscosity he observed under uniaxial pressure. He also finds that increasing the equilibration time at pressure, with the field off, decreases the subsequently acquired viscous magnetization. Samples subjected to hydrostatic pressure do not experience pressure gradients and thus they are less likely to be affected by diffusion processes. Diffusion processes have activation times that are generally much shorter than magnetic viscosity that may occur geologically over millions of years (Moskowitz, 1985; Halgedahl, 1993). Thus, these diffusion processes may have dominated previous viscosity experiments under uniaxial pressure, but are likely to be less important for in situ viscosity, especially when the dominant component of the natural stress is hydrostatic pressure, as in the lower crust.

There was no systematic change in the pressure dependence of the VRM results over the grain size range of the synthetic multidomain magnetite studied. Magnetic grain sizes for the synthetic samples varied form $1 \mu \mathrm{m}$ to $<100 \mu \mathrm{m}$ based on their hysteresis properties (Worm and Markert, 1987b). This is consistent with previous ambient pressure results at both room temperature (Dunlop, 1983) and at elevated temperature (Kelso and Banerjee, 1994), where no consistent change in the $S_{a}$ value was observed over this grain size range.

Elevated temperature viscous magnetization characteristics for three of these samples have been reported in a previous

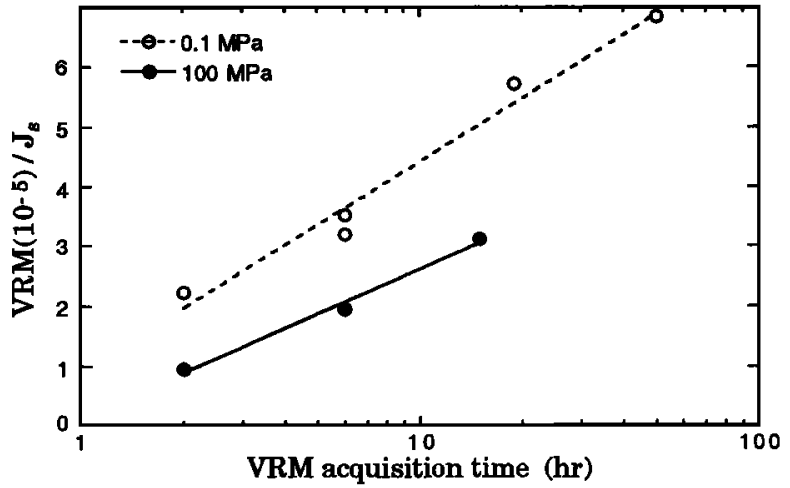

Figure 3. Viscous remanence acquisition data for glass ceramic sample GC2a at ambient conditions $(0.1 \mathrm{MPa}$ and $\left.22^{\circ} \mathrm{C}\right)$ and at elevated pressure $\left(100 \mathrm{MPa}\right.$ and $\left.22^{\circ} \mathrm{C}\right)$.

study by Kelso and Banerjee (1994). At one atmosphere pressure there was approximately a factor of three increase in the viscosity coefficient for these samples between room temperature and $400^{\circ} \mathrm{C}$. Thus for anomaly sources that reside at both elevated temperature and pressure within the earth, the thermal enhancement of magnetic viscosity will dominate over effects due to hydrostatic pressure, assuming that our results for three orders of magnitude of pressure (0.1-100 MPa) can be extrapolated over the range of conditions experienced in the crust, i.e., $0.1-1500 \mathrm{MPa}$, and if the temperature and pressure effects can be added linearly.

\section{Conclusions}

The rate of VRM acquisition with $\log$ (time) is approximately linear at both 0.1 and $100 \mathrm{MPa}$ hydrostatic pressure. Magnetic grain size does not significantly affect the hydrostatic pressure dependence of VRM acquisition over the multidomain size range studied. Hydrostatic pressure does not significantly affect the rate of VRM acquisition over the pressure range from 0.1 to $100 \mathrm{MPa}$ for either natural or synthetic samples with multidomain magnetite as the dominant magnetic mineral. This is in great contrast to previous results on the effect of uniaxial pressure on the viscous magnetization of titanomagnetites (Pozzi, 1970; Bezuglaya et al., 1973; Spörer; 1984) which observed significant increases in viscous magnetization, from two to six times, at differential stresses

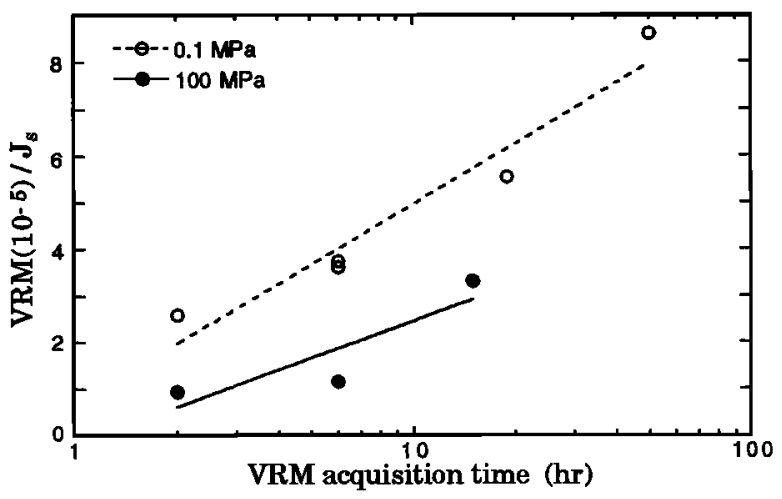

Figure 4. Viscous remanence acquisition data for glass ceramic sample GC3a at ambient conditions (O.1 $\mathrm{MPa}$ and $22^{\circ} \mathrm{C}$ ) and at elevated pressure $\left(100 \mathrm{MPa}\right.$ and $\left.22^{\circ} \mathrm{C}\right)$. 
of less than $50 \mathrm{MPa}$. Taking into consideration our previous work (Kelso and Banerjee, 1994) on the temperature dependence of VRM for these samples, thermal effects likely dominate over hydrostatic pressure effects for coarse-grained magnetites that acquire VRM at depth through geologic time. Theoretical models of the viscous magnetization of multidomain materials may neglect the effect of hydrostatic pressure as a first order approximation. Future models must more importantly address the effect of energies involved in domain wall nucleation and denucleation and domain wall stabilization due to, for example, defects and diffusion processes. Hydrostatic pressure often effects the magnitude and type of diffusion in rocks while previous studies have shown that VRM acquisition is sensitive to differential stresses, therefore, future studies should also examine the effect of hydrostatic pressure on VRM when differential stress is also present.

Acknowledgments. We thank David Kohlstedt for the use of his high pressure laboratory facilities and for discussions during all stages of this project. P.K. thanks Quan Bai, Martha Daines and Mark Zimmerman for their assistance with the elevated pressure apparatus. We also thank Bruce Moskowitz, Joe Hodych, Mike Fuller and Ron Merrill for critical comments on earlier drafts of this manuscript. This project was supported by NASA grant NGT-50421 and a doctoral dissertation fellowship from the University of Minnesota. We wish to thank the Institute for Rock Magnetism (IRM) in Minneapolis for the use of its facilities. The IRM is funded by the Keck Foundation, the National Science Foundation, and the University of Minnesota. This is IRM contribution number 9402 .

\section{References}

Bezuglaya, L. S., S. K. Maksudov and Y. P. Skovorodkin, Viscous magnetization of rocks under pressure, Izv. Akad. Nauk SSSR Ser. Fiz. Zemli (Phys. Solid Earth), 9, 110-113 (268-270 in Engl. transl.), 1973.

Dunlop, D. J., Theory of magnetic viscosity of lunar and terrestrial rocks. Rev. Geophys. Space Phys., 11, 855-901, 1973.

Dunlop, D. J., Viscous magnetization of 0.04-100 $\mu \mathrm{m}$ magnetites, $J$. Geophys., 74, 667-687, 1983.

Fountain, D. M., Growth and modification of lower continental crust in extended terrains: the role of extension and magmatic underplating. In Properties and Processes of Earth's Lower Crust, edited by R. F. Mereu, S. Mueller and D. M. Fountain, pp. 287-299, AGU, Washington, D.C., 1989.

Hahn, A. G. and H. A. Roeser, The magnetization of the lower continental crust, In Properties and Processes of Earth's Lower Crust, edited by R. F. Mereu, S. Mueller and D.M. Fountain, Pp. 247-253, International Union of Geodesy and Geophysics, Washington, 1989.

Halgedahl, S. L. Experiments to investigate the origin of anomalously elevated unblocking temperatures. J. Geophys. Res., 98, 22,44322,460, 1993.

Kapicka, A., Variations in mean susceptibility of rocks under hydrostatic and non-hydrostatic pressure, Phys. Earth Planet. Inter., 63, 78-84, 1990.

Kapicka, A., Magnetic susceptibility under hydrostatic pressure of synthetic magnetite samples, Phys. Earth Planet. Inter., 70, 248-252, 1992.

Kelso, P. R., A magnetic study of deep crustal rocks from Arunta Block, central Australia, and the implication for the interpretation of long wavelength magnetic anomalies, Ph.D. thesis, 131 pp., University of Minnesota, 1993.

Kelso, P. R., S. K. Banerjee and C. Teyssier, The rock magnetic properties of the Arunta Block, central Australia and their implication for the interpretation of long wavelength magnetic anomalies, $J$. Geophys. Res., 98, 15,987-15,999, 1993.

Kelso, P. R. and S. K. Banerjee, An experimental study of the temperature dependence of viscous remanent magnetization of coarse grained natural and synthetic magnetite, Earth Planet. Sci. Lett., 122, 43-56, 1994.

Martin, R. J., III, Is piezomagnetism influenced by microcracks during cyclic loading?, J. Geomagn. Geoelectr., 32, 741-755, 1980.

Mayhew, M. A. and J. L. LaBrecque, Crustal geologic studies with MAGSAT and surface magnetic data, Rev. Geophys., 25, 971-981, 1987.

Moskowitz, B. M., Magnetic viscosity, diffusion after-effect, and disaccommodation in natural and synthetic samples, Geophys. J. $R$. Astr. Soc., 82, 143-161, 1985.

Nagata, T. and H. Kinoshita, Effect of hydrostatic pressure on magnetostriction and magnetocrystalline anisotropy of magnetite. Phys. Earth Planet. Inter., 1, 44-48, 1967.

Nulman, A. A., V. A. Shapiro, S. I. Maksimovskikh, N. A. Ivanov, J. Kim and R. S. Carmichael, Magnetic susceptibility of magnetite under hydrostatic pressure, and implications for tectonomagnetism, $J$. Geomagn. Geoelectr., 30, 585-592, 1978.

Pozzi, J.-P. and M. É. Thellier, Observation des changements du trầnage magnétique d'une roche comprimée, C. R. Acad. Sci. (Paris), Sér. B, 271, 820-823, 1970.

Samara, G. A. and A. A. Giardini, Effect of pressure on the Neel temperature of magnetite, Phys. Rev., 186, 577-580, 1969.

Schlinger, C. M., Magnetization of lower crust and interpretation of regional magnetic anomalies: example from Lofoten and Vesterålen, Norway, J. Geophys. Res., 90B, 11,484-11,504, 1985.

Schult, A., Effect of pressure of the Curie temperature of titanomagnetites [(1-x) $\cdot \mathrm{Fe}_{3} \mathrm{O}_{4}-\mathrm{x} \cdot \mathrm{TiFe}_{2} \mathrm{O}_{4}$ ], Earth Planet. Sci. Lett., 10, 8186, 1970.

Shive, P. N. and D. M. Fountain, Magnetic mineralogy in an Archean crustal section: implications for crustal magnetization. J. Geophys. Res., 93B, 12,177-12,186, 1988.

Spörer, H., On viscous remanent magnetization of synthetic multjdomain magnetite, Geophys. Res. Lett., 11, 209-212, 1984.

Toft, P. B. and S. E. Haggerty, Limiting depth of magnetization in cratonic lithosphere, Geophys. Res. Lett., 15, 530-533, 1988.

Wasilewski, P. J. and R. D. Warner, Magnetic petrology of deep crustal rocks-Ivrea Zone, Italy, Earth Planet. Sci. Lett., 87, 347-361, 1988.

Williams, M. C., P. N. Shive, D. M. Fountain and R. B. Frost, Magnetic properties of exposed deep crustal rocks from the Superior Province of Manitoba, Earth Planet. Sci. Lett., 76, 176-184, 1985/86.

Worm, H.-U. and H. Markert, The preparation of dispersed titanomagnetite particles by the glass-ceramic method, Phys. Earth Planet. Inter., 46, 263-270, 1987a.

Worm, H.-U. and H. Markert, Magnetic hysteresis properties of fine particle titanomagnetites precipitated in a silicate matrix, Phys. Earth Planet. Inter., 46, 84-93, 1987b.

Paul R. Kelso, Department of Geology and Physics, Lake Superior State University, Sault Ste. Marie, MI 49783 (email: pkelso@lakers.lssu.edu)

Subir K. Banerjee, Department of Geology and Geophysics, Institute for Rock Magnetism, University of Minnesota, Minneapolis, MN 55455

(Received August 8, 1994; Accepted October 19, 1994) 